\title{
A MODIFIED METHOD FOR THE CALIBRATION OF WARBURG FLASKS AND MANOMETERS
}

\author{
by \\ A. G. ZWART \\ Laboratory for Physiological Chemistry, The University, Utrecht (Netherlands)
}

During the last few years several methods have been described for the calibration of Warburg flasks and manometers with mercury ${ }^{1,2,3}$.

Although in all these methods the calibration is carried out in two steps, so that it can easily be performed by one operator, they have the disadvantage, in our view, that the flasks must always be filled with so much mercury that it exactly reaches a predetermined mark on the side-arm capillary when the flask is seated on the ground joint of the manometer. This adjustment of the volume of mercury gives unnecessary and time-consuming work.

The following method, which does not possess this difficulty, is very rapid, and has given complete satisfaction in our laboratory for a number of years.

a. Flask $F$ is filled with so much mercury, paying due attention to the removal of trapped air bubbles, that when it is connected to the manometer in position $r$, the mercury rises to some arbitrary point $M_{1}$ in side-arm capillary $C_{1}$. This point is marked with a glass-marking pencil. Flask $F$ is detached and the mercury is poured into a tared beaker.

b. With the manometer in position 2 , a short rubber tube $R$, closed at one end with a short piece of glass rod and filled with mercury, is pushed over the capillary at opening $T_{1}$, while stopcock $S$ is open. The rubber tube is pushed on so

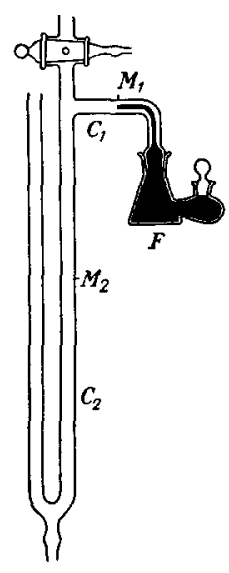

Position 1 far, and the manometer held at such an angle, that the mercury simultaneously rises to mark $M_{1}$ on side-arm capillary $\mathrm{C}_{1}$ and to the reference mark $M_{2}$ on capillary $C_{2}$ (usually $160 \mathrm{~mm}$ ). The stopcock is closed in such a manner that the tail end communicates with the capillary above the stopcock at $T_{1}$, and the rubber tube and the mercury in the capillary above the stopcock are removed. The manometer is now tilted to position 3 , with opening $T_{2}$ above the tared beaker (that already contains the mercury from flask $F$ ), and the mercury is allowed to run out at $T_{2}$ by pulling out stopcock $S$ (it cannot be opened, because then the mercury in the bore would also run out).
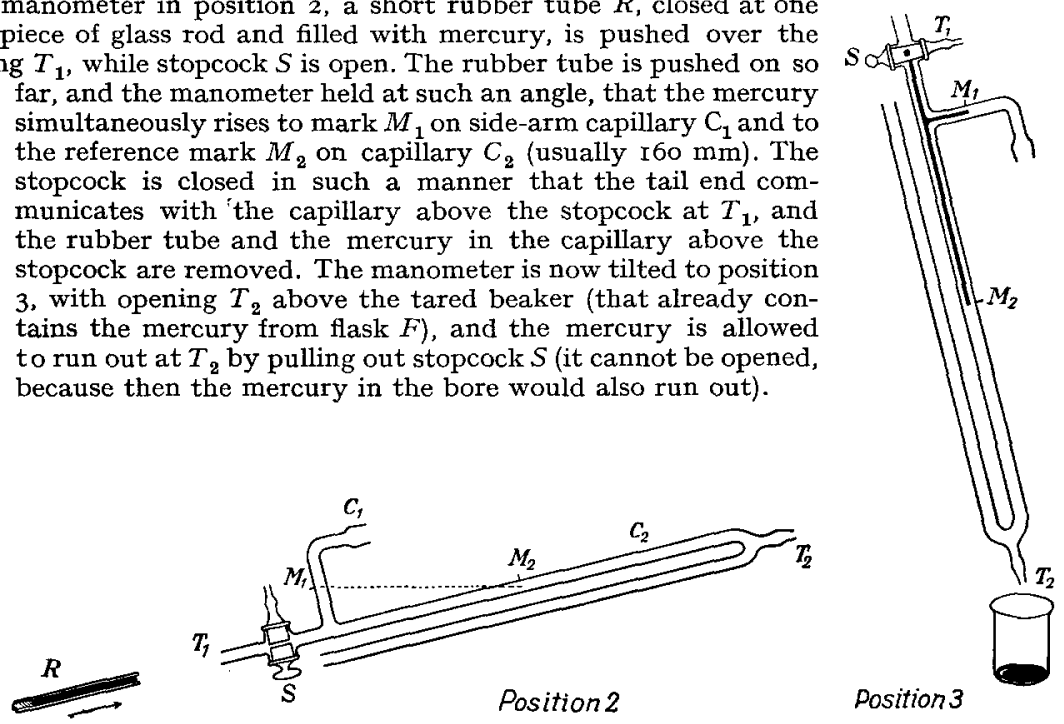

c. The temperature of the mercury is measured, and it is weighed to the nearest tenth of a gram. The volume of flask plus manometer to the zero point reference mark can now be calculated.

\section{REFERENCES}

1 R. H. BURRIS AND R. W. MCGIlvery in UMbreit, BuRris AND Stauffer, Manometric Techniques and Tissue Metabolism, and edition, p. 50, Minneapolis, I95I.

2 W. F. Loomis, Science, rog (I949) 49 r.

3 J. W. TiEman AND J. V. Beck, Experientia, 7 (I95I) 389. 